\title{
PERICULOSIDADE E CONTROLE SOCIAL
}

\section{Danielle Angélica Polastri Mendonça}

Graduanda do 9 Período da PUC Minas Belo Horizonte - Unidade São Gabriel e-mail: dani_angelica@hotmail.com

RESUMO: O trabalho retrata a falência do instituto da medida de segurança. A fundamentação na periculosidade evidencia um meio de controle e exclusão social. Com base no marco teórico da criminologia crítica, visualiza-se o preconceito e o detrimento dos direitos individuais em relação à proteção do meio social. No decorrer de um processo histórico, o louco, não se enquadrando às regras sociais e sendo considerado improdutivo à sociedade, foi excluído do convívio social. A segregação é justificada pelo perigo que o louco representaria à sociedade, difundido pelo Direito Penal, instrumento de legitimação do controle social. O poder jurisdicional de punir não mais é utilizado sobre infrações, mas sobre indivíduos, não mais pelo que fizeram, mas pelo que representam. O doente mental é rotulado como perigoso, obtendo da sociedade, como respostas automáticas do medo, a indiferença e o castigo coercitivo. Assim, o processo de ressocialização muitas vezes não se efetiva, transformando hospitais psiquiátricos em depósitos humanos. A medida de segurança deveria ser reavaliada, não ocorrendo punições perpétuas, não ferindo assim o Estado Democrático de Direito. Com isso, o louco não exerce seu papel social, sendo que o Direito Penal acaba por efetivar tal processo se fundamentando na idéia de que pode trazer perigo para toda uma sociedade, ferindo a esfera dos direitos fundamentais da pessoa humana.

PALAVRAS-CHAVE: Direito penal; Medida de segurança; Periculosidade; Medo; Controle social. 


\section{INTRODUÇÃO}

A relação da loucura com a sociedade pode ser vista por dois ângulos que se complementam. O primeiro poderíamos determinar de um lado fantasioso, no qual os loucos seriam seres detentores de mentes extraordinárias capazes de alucinações inimagináveis pelos seres normais. Seriam seres que vivessem com a mente em outra realidade, não conseguindo acompanhar as normas sociais. Esses loucos são retratados em contos literários, pela mídia, em novelas e no cinema como cientistas inescrupulosos, serial-killers, indivíduos que se julgam dotados de poderes etc.

Porém, a outra maneira de se visualizar o doente mental é com frieza, indiferença e medo. Contaminados por essa imagem de terror que os loucos representam ao longo dos tempos, a sociedade tende a querer um afastamento desses "anormais". Tal afastamento é construído baseado na concepção de que o louco é um indivíduo que não se adapta às normas morais e sociais, não trabalha, não produz. Ou seja, não se adapta aos interesses do poder dominante. Assim, o louco é um indivíduo diferente, que, por não respeitar a lógica do sistema, traria abalos para a ordem social. O perigo que representaria o doente mental surge da necessidade de se ter um controle do indivíduo desviante.

Assim, caberia ao Direito Penal exercer um poder de controle e defesa social. Os indivíduos que não respeitam as normas são exilados, afastados do convívio social, para que, em penitenciárias, aprendam a se ressocializar. No caso do louco criminoso, diferente dos presos, não possui capacidade de ter consciência do ilícito, é um inimputável, e por isso representa um perigo à sociedade. Assim, enquanto não cessada a periculosidade do doente mental, este acaba por ser mantido em um manicômio judiciário, para receber o tratamento determinado.

Nesse estabelecimento psiquiátrico, o louco criminoso receberia, teoricamente, o tratamento adequado para possivelmente reestruturar seus valores morais e sociais, obtendo a cura e voltando, assim, para o convívio social. Porém, o que se percebe é que o doente mental muitas vezes não recebe o tratamento almejado, além de ser impossível para muitos alterar seu psíquico, tendo um tratamento eterno, transformando os manicômios em depósitos humanos. 
Assim, leis, juristas por todo o mundo, justificaram por muito tempo e ainda reafirmam a periculosidade do louco, devendo ser exilado do convívio social pela segurança de todos os homens. Por trás de todo um sistema de leis e normas, o que se percebe é uma sociedade ambiciosa, excludente, que não dá espaço ao diferente. Utilizando-se do argumento de defesa social, essa sociedade desrespeita os direitos humanos como a dignidade de um ser humano, que é o doente mental.

\section{A EVOLUÇÃO DA PERICULOSIDADE}

Em Roma, por meio dos relatos contidos nos Digestos, percebe-se que os romanos já se preocupavam com os doentes mentais, denominando-os de furiosi, que eram excluídos do Direito Penal, mas se lhes impunha um estado de simples custódia, para os loucos criminosos, e uma medida intermediária entre a pena e a simples custódia, para os loucos não criminosos.

$\mathrm{Na}$ antiga Europa existiam rumores bastante difundidos sobre a noção de periculosidade, que, apesar de ainda não consolidada pelas legislações, na prática já encontrava sua atuação na discriminação de loucos, mendigos, doentes. "Em 1524 foi imposto aos indigentes abandonar Paris ou trabalhar'." (PIEDADE JÚNIOR, 1982, p.78).

Durante a Idade Média, os crimes mais praticados eram os crimes "sangrentos", ou seja, agressões físicas, homicídios, que eram punidos severamente, com mutilações, enforcamentos, demonstrações de sofrimento em praça pública. Porém, com a transição do feudalismo para o capitalismo, surge com as idéias renascentistas, e posteriormente com o lluminismo, a concepção burguesa da propriedade e sua importância na sociedade. Assim, no final do século XVII e início do século XVIII, houve uma nova concepção de punição, percebendo-se uma redução nos crimes violentos e um aumento dos delitos contra a propriedade. Iniciase um deslocamento global da ilegalidade do ataque aos corpos para um desvio um pouco mais intenso para os bens.

Com isso, a modificação social, seja no interesse econômico, seja no crescimento demográfico ou na multiplicação de riquezas e propriedades, faz surgir uma necessidade de segurança como conseqüência de todo esse processo. A segurança vem para as pessoas, mas para, principalmente, conservar suas posses 
e manter a estrutura econômica vigente. Conclui-se que a segurança vinha para a classe rica da sociedade, a burguesia, detentora de poder e riquezas.

Puniam-se os ladrões por violar o bem jurídico propriedade, mas se punia os vadios, os inválidos, assim como os loucos, por não contribuírem para a lógica do sistema capitalista: trabalhar-receber-adquirir posse. Os loucos eram temidos pelo seu perigo a cada indivíduo, sendo vistos muitas vezes como "monstros ensandecidos" capazes das piores atrocidades. Ademais, não eram capazes de absorver a idéia do sistema, trabalhar, ser explorado, gerar riqueza, representando apenas gastos inúteis. Muitos na época eram adeptos a entregá-los ao Estado, pertencendo-Ihe como escravos, por representarem inutilidade e perigo. Texto citado por Foucault (2001) ilustra tal realidade:

Enfim, há condenados "inaptos ou incapazes" que uma "organização incompleta torna impróprios para qualquer ocupação que exija esforços pensados e força de vontade, que se encontram então na impossibilidade de sustentar a concorrência dos trabalhos com os operários inteligentes, e não tendo nem instrução bastante para conhecer os deveres sociais, nem inteligência bastante para compreendê-los e combater seus instintos pessoais, são levados ao crime por sua própria incapacidade. Para esses, a solidão só servia para fomentar a inércia; devem portanto viver em comum, mas de maneira a formar grupos pouco numerosos, sempre estimulados por ocupações coletivas, e submetidos a uma vigilância rígida. (FOCAULT, 2001, p.67).

Mas foi somente com o Código Penal Francês de 1810 que houve a instalação de medidas de caráter preventivo e de terapia para aqueles que houvessem agido sem discernimento. Esse Código, no final do seu artigo 64, previa não haver crime, nem delito, se o infrator estivesse no estado de demência no instante do ato. A invocação da loucura excluía o crime, ou seja, para o autor louco desapareceria o crime. O diagnóstico da loucura interrompia o processo e retirava o poder da Justiça sobre o autor do ato.

Posteriormente, no século XIX, houve grandes discussões acerca do artigo 64, admitindo, então, ser possível alguém ser culpado e louco, mas numa lógica inversamente proporcional: quanto mais louco, menos culpado, mas devendo ser enclausurado, tratado, mas não punido.

Outro marco foi quando surgiram as idéias positivistas, influenciando em toda concepção do Direito Penal da época, nas medidas preventivas de crime, 
protetoras da sociedade, seja a prisão, seja a medida de segurança. Para eles, a prisão agravava mais ainda os impulsos criminosos do condenado, em vez de reduzi-los. O Direito Penal tinha que mudar de rumo, pois as novas exigências da vida social não se enquadravam nos ideais clássicos de justiça e retribuição da pena.

Com isso, a defesa social deveria ser o fim do Direito Penal. Sem anular a prevenção geral, pela intimidação, ganhava destaque a prevenção especial, atuando sobre o próprio criminoso para reintegrá-lo na comunidade de Direito, ou inocuizá-lo, pela segregação do meio, quando resistente ao processo de correção.

Dessa dualidade de concepções, retribuição e defesa social, surge um novo grupo de medidas, que consideram somente o potencial de criminalidade do homem, com a necessidade de uma defesa eficaz. Assim, a idéia de defesa social estimula a utilização das medidas de segurança, ampliando a concepção de periculosidade, de homens loucos, delinqüentes, que abalam a ordem, trazendo perigo a toda estrutura social, necessitando, pelo bem de uma comunidade, serem exilados em manicômios, hospícios.

Consolidava-se, assim, a idéia de periculosidade criminal, com a utilização das medidas de segurança, instituto que teria por fim não punir, mas corrigir ou segregar, de acordo com o Código Penal Italiano de 1889, conhecido como o Código Zanardelli. Mas a sistematização da medida de segurança se deve a Carl Stoss, em seu projeto para o Código Penal Suíço. A partir daí, houve a formação do Congresso da União Internacional de Direito Criminal, com o objetivo de discutir a constituição e os efeitos da Medida de Segurança, já que para os criminalistas da época havia mais uma nova preocupação, "o estado perigoso". Doutrinadores chegaram à conclusão de ser estritamente necessária a utilização da medida de segurança, já que o bem-estar e a ordem social devem ser mantidos sempre.

Assim, as idéias de defesa social e de periculosidade são espalhadas pelo mundo, influenciando, até hoje, o Direito Penal vigente nos países. Com isso, tornase inerente ao ser humano excluir o indesejado, temer o perigoso. 


\section{A INFLUÊNCIA SOBRE BRASIL}

Durante o período colonial, nas ordenações Afonsinas, Manuelinas e Filipinas houve um registro de uma preocupação maior com o crime, não se voltando para o protagonista e sua personalidade. Não havia preceitos gerais que referissem a imputabilidade e inimputabilidade.

O Código Criminal do Império determinava apenas que os loucos que tivessem cometido crimes deveriam ser entregues para responsabilidade de seus familiares ou recolhidos em locais destinados a eles. Em meados do século XIX, mais precisamente em 1852, é criado, no Rio de Janeiro, um hospício destinado ao tratamento de alienados, sendo o primeiro hospital de doentes mentais do Brasil.

O Código Penal da República de 1890 possui conceitos de moral e religião, pecados e vícios. Assim, foi abandonada de vez toda idéia de penas cruéis, como a pena de morte, que ainda se utilizava. Tal Código foi completamente influenciado pelos ideais da Escola Clássica, principalmente o caráter de retribuição da pena. As idéias de Rousseau, Hobbes e Montesquieu de livre-arbítrio e inteira responsabilidade do indivíduo por suas ações, sendo considerado o elemento mais repugnante e inimigo da sociedade aquele que quebrasse o contrato social firmado entre os homens.

Contemplava ainda o exposto no Código anterior, de que os loucos deveriam ser entregues à família ou, em casos extremos, ao recolhimento em hospitais para alienados, não importando o tempo de internamento. Só incidia imputabilidade aos indivíduos inteligentes, capazes de possuir a intenção criminosa. Assim, não eram considerados criminosos os casos de imbecilidade nativa, enfraquecimento senil e doentes mentais, pois não detinham o conhecimento de fato ilícito.

Em 1937, Getúlio Vargas tomava o poder iniciando o período de industrialização do Brasil. A única modificação que fez ao Código passado foi a determinação da criação de manicômios criminais para os loucos criminosos recolhidos.

No Código de 1940, houve grande influência das idéias positivistas de defesa social. Primeiramente, no início da década, doutrinadores já discutiam sobre a função de intimidação e regeneração da pena, devido ao grande crescimento de reincidentes. Com a reincidência, surgia a idéia de homens inadaptáveis às normas 
sociais, indivíduos que sempre causariam novas delinqüências. Assim, esses homens se tornavam eternos inimigos da sociedade por representarem risco a ela. Do determinismo comportamental, surgia, então, a periculosidade criminal.

A medida de segurança desvincula-se da idéia central da pena, sendo destinada para o uso exclusivo da periculosidade do agente, sendo aplicada aos indivíduos imputáveis e inimputáveis que sejam criminalmente perigosos. As medidas de segurança de caráter pessoal foram especificadas como internação em manicômios judiciários, casas de custódia e tratamento, ou ainda em colônias agrícolas ou de trabalho.

A responsabilidade do agente passa a ser de cunho social, sendo que o criminoso que agiu independentemente de sua vontade, determinado por circunstâncias físico-psíquicas ou do meio, mas trouxe um abalo social, representaria um perigo e deveria ser temido. O louco, agora, conforme as idéias lombrosianas, é rotulado como ser que sempre foi e será perigoso à sociedade, devendo ser exilado desta. Nelson Hungria, doutrinador da época, defende e indeterminação da medida de segurança, pois sua duração deverá perdurar enquanto durar o estado perigoso do indivíduo perante a sociedade, mesmo que nunca acabe. Para ele, o louco é um ser perigoso que deve ser detido.

Com a entrada do período militar, houve a criação do Código Penal Militar de 1969, que se assimilava às idéias positivistas, glorificando ainda mais a defesa social e o exílio de qualquer indivíduo que fosse maléfico para a sociedade e a nação, fossem eles inimputáveis ou imputáveis a crime. A idéia de medida de segurança sem previsão de duração de tempo e periculosidade foram mantidas idênticas ao código anterior. Têm-se relatos de que os manicômios judiciários foram utilizados para a internação forçosa de presos políticos contrários ao governo.

Posteriormente ao período militar, a redemocratização revoga o Código de 1969, adotando novamente o de 1940, sendo feitas poucas mudanças, apenas a consolidação do sistema vicariante: pena para os imputáveis, medida de segurança pra os inimputáveis. Mas a idéia de periculosidade e indeterminação da medida de segurança são não só mantidas, como reafirmadas por muitos doutrinadores até hoje. 


\section{A Periculosidade como Forma de Controle Social}

O Código Penal tipifica os crimes e delitos, mas o criminoso não é julgado apenas pelo objeto jurídico definido na Lei, mas julgam-se também paixões, instintos, anomalias, enfermidades, inadaptações, os efeitos do meio ambiente. Estes pontos são trazidos à tona para explicar os fatos julgados e determinar até que ponto a vontade do réu estava envolvida no crime.

Porém, tais circunstâncias são respostas insuficientes, pois nunca irão demonstrar a verdadeira realidade, influenciando para um julgamento tendencioso devido a um momento. O conhecimento do criminoso, a apreciação que se tem dele, suas relações, seu passado e sua possível atitude em um futuro são momentos que rotulam o indivíduo, como no caso do inimputável, do louco, tal marcação poderá muitas vezes acompanhá-lo por toda a vida.

Observa-se, como exemplo, que no início do século XIX os loucos eram caracterizados em laudos, circulares, como "monstros", possuidores de "anomalias psíquicas", os "pervertidos", de forma que, na tentativa de explicar um ato, acabavase por qualificar o indivíduo com tal e única determinação, ficando impregnada à sua personalidade tal circunstância, que traria à sociedade uma única visão: perigo. Assim, não mais se preocupava em sancionar a infração, mas controlar o indivíduo, neutralizar sua periculosidade, modificar suas disposições criminosas e cessar somente após obtenção de tais modificações.

Com isso, o poder jurisdicional de punir não é mais utilizado sobre infrações, mas sobre os indivíduos; não mais sobre o que fizeram, mas pelo que eles são, foram ou possam ser. Condenar ou absolver não é simplesmente um julgamento de culpa, uma decisão legal que sanciona, mas uma apreciação da personalidade do indivíduo, de sua "normalidade".

Os próprios peritos psiquiatras hoje acabam contaminando a visão que se tem dos doentes mentais, quando, mediante seus laudos, avaliam se indivíduo é acessível à pena, se apresenta alguma periculosidade, se é curável ou readaptável. Entram no mérito da administração da pena, sua necessidade, sua utilidade, sua eficácia possível, se é melhor hospício ou prisão, um enclausuramento breve ou longo, tratamento médico ou internamento em manicômio. Assim, a perícia médica acaba por sugerir uma receita para o juiz designar ao indivíduo. O discurso penal e 
psiquiátrico se confundem em suas fronteiras, sendo aí seu ponto de junção, formando a noção de indivíduo "perigoso" que permite estabelecer uma rede de causalidade entre a biografia inteira e a punição-correção.

Assim, o objetivo social é controlar o louco que traz perigo à sociedade. Umas das formas de controle pode ser exercida pelo exame. $O$ exame combina as técnicas de hierarquia que vigia e as da sanção que normaliza. É um controle normalizante, uma vigilância que permite classificar, qualificar e punir.

O exame ao doente mental, ao louco, desde o realizado na fase do processo, aos periódicos durante o internamento, permite conhecer e controlar o indivíduo. Quando se tem uma descrição do ser, seu relato de vida, seus hábitos, sua historiografia, tudo faz parte de um poderio de quem os possui. $\mathrm{O}$ indivíduo passa a ser um estudo de "caso", objeto para conhecimento e uma tomada para o poder. É mediante o exame que se terá uma noção de quem é o indivíduo, de como está, será classificado e o que fazer com ele.

O poder, que utiliza o exame como meio para manutenção, cria a realidade que deseja ser mais conveniente para seus objetivos. O poder exclui, censura, esconde, reprime, mas também produz realidade, sendo que o indivíduo e o conhecimento que se possa ter dele se originam dessa produção. O indivíduo acaba se tornando uma representação da ideologia da sociedade, uma realidade fabricada. O louco, então, será uma realidade produzida pelo poder: ele passa a se destacar dos outros indivíduos, pois nele são impregnadas características que o tornam desviante do normal seguido por todos, passando a ser individualizado e, com isso, será inepto ao convívio social.

Análogo a tal exclusão da loucura foi o ocorrido com leprosos e pestilentos em épocas passadas. A lepra ocasionou a separação e distribuição de indivíduos que eram rejeitados pela sociedade. Eram enviados para exílios longe dos centros urbanos, representando o sonho político de uma sociedade pura. Já a peste, ocasionou a prisão dos temidos sociais. Eram obrigados a ficar retidos em suas próprias casas, representando um severo controle disciplinar em que, pela salvação social, cada indivíduo era obrigado a obedecer a ordens. Mas ambas repartem um mesmo contexto social: perigo, temor e controle, seja com o exílio dos leprosos, seja com a prisão dos pestilentos. Duas maneiras de exercer poder sobre os homens, de controlar suas relações, de desmanchar suas perigosas misturas. 
Assim, os loucos são hoje os habitantes simbólicos dos leprosos e pestilentos: primeiramente por serem excluídos do campo social, por apresentarem "anormalidades" incompatíveis com a vida social e, também, a partir daí, serem projetados nos ditames disciplinares, sendo individualizados, excluídos, colocados em manicômios judiciários. Todo e qualquer indivíduo que represente um "perigo" para a sociedade, ou pelo menos apresenta um "perigo" para os interesses de uma classe dominante, será diferenciado dos demais, havendo uma campanha social para a repulsa a este. Foi o que ocorreu com os comunistas e os opositores políticos.

Ocorre a repartição do controle individual funcional, iniciando-se na marcação e diferenciação: louco e não-louco, perigoso e não-perigoso, normal/anormal; e, posteriormente, na determinação coercitiva, representando pelos exames psiquiátricos de quem é ele, onde deve estar, como reconhecê-lo, caracterizá-lo, entregando-o a instituições que assumem como tarefa medir, controlar e corrigir os anormais.

Essas instituições fazem transparecer a função almejada de transformar os loucos. Por meio do isolamento, com um tratamento, o indivíduo poderia novamente se "tornar social" e se readaptar a sociedade. Porém, até que isso não fosse obtido, o doente mental deveria ser mantido longe dos outros seres humanos, para não causar qualquer dano.

\section{A Perda do Papel Social e Humano do Internado}

As instituições destinadas a pessoas socialmente perturbadoras, como hospitais, instituições para veteranos de guerra, cadeias, clínicas geriátricas, hospitais psiquiátricos, de um modo geral, têm tendências de "fechamento" para o mundo. Para isso, criam barreiras com o exterior, causando a ruptura com o mundo e a desconfiguração da identidade, da personalidade do internado. Tal processo é percebido enfatizadamente em se tratando de manicômios judiciários e hospitais psiquiátricos, pois o indivíduo já é caracterizado antes e durante todo o processo de internamento como anormal, diferente, inválido como ser humano.

A mutilação do "eu" pode ser percebida primeiramente no processo de admissão: tirar fotografia, atribuir números, impedir a posse de bens pessoais, 
despir, dar banho, desinfetar, distribuir roupas apropriadas da instituição. Assim, esse processo de "arrumação" pode ser definido como enquadramento do internado à máquina administrativa do estabelecimento.

Pode surgir ao internado um sentimento de insegurança que pode ocasionar desconfiguração de sua personalidade, quando é tratado como um animal, sem o mínimo de higiene e de dignidade humana, como em muitos locais que ainda usam pancadas, terapia de choque, lesando sua integridade física, mesmo que a equipe médica diga ser necessário.

O próprio tratamento que o internado recebe o coloca em posição secundária, pois em muitos locais as afirmações feitas por eles são desprezadas pela equipe do estabelecimento, muitas vezes não recebendo cumprimentos, comprovando, assim, que não são tratados como seres humanos precisando de tratamento, doentes, mas seres inferiores, anormais, objetos, que não necessitam de atenção, dignidade que qualquer homem teria.

Isso ocorre porque a equipe dirigente da instituição não possui o olhar imparcial almejado pela teoria. Os funcionários que atuam com os doentes mentais, loucos, já trazem conceitos predefinidos de uma sociedade preconceituosa e excludente, que afirma veemente o perigo de todos os doentes mentais a qualquer ser humano, fazendo impregnar no interior de cada funcionário o medo aos internos, pois muitas pessoas da equipe dirigente crêem que muitos pacientes são perigosos, podendo bater "sem razão" e ferir um funcionário. Assim, uma resposta automática a esse medo é a indiferença, é castigar o transgressor, negativa e coercitivamente, dando um tratamento estúpido, levando muitas vezes à desconsideração de ser como humano.

Deve-se sempre conscientizar a equipe dirigente das obrigações que cada um tem respeitar os direitos dos pacientes, conscientizando-os que não são monstros perigosos, são seres humanos precisando de tratamento, pois toda a equipe é essencial para um bom aproveitamento do tratamento pelo internado. Seja uma enfermeira, que cuida, prepara o paciente, seja o médico psiquiatra que o avalia internamente, todos exercem uma intervenção no "eu" do internado, pois não deixam de ser contatos sociais.

Sendo vigiado e observado a todo momento o indivíduo perde sua liberdade de ação, já que para a instituição toda atitude que o doente mental apresenta deve 
ser analisada como procedente e improcedente ao tratamento, sendo que o doente acaba por perceber tal situação, sentindo-se incomodado, vigiado, desconfortável.

Ademais, a equipe dirigente muitas vezes está limitada a registrar apenas pontos negativos, atos de desobediência do paciente, pois algumas atitudes dentro da instituição não podem ser consideradas realizadas também fora delas (por exemplo, quando um comportamento era feito especialmente por causa de uma pessoa ou um hábito, ou um ambiente), e outras formas de comportamento errado são respostas a situações em que o paciente era colocado involuntariamente. "Portanto, ocorre uma refração do comportamento, e as paredes da instituição atuam como um prisma grosso e deformado". (GOFFMAN, 2001, p.292).

O indivíduo acaba por ter reações não esperadas, como se comportar diversamente ao esperado, tendo resultados negativos, pois não está agindo numa posição e num mundo que foram programados para ele.

Tais fatos podem gerar como conseqüências: um afastamento do interno, caracterizado pela regressão, alienação, quando o internado aparentemente deixa de dar atenção a tudo; quando fica intransigente, não aceita cooperar com nada imposto, podendo, em algumas instituições, ter como resposta tratamentos de choque, por exemplo, para manter o paciente conivente com o sistema; ou uma aceitação completa do apresentado a ele, em que sua personalidade é tão deteriorada que ele se torna submisso a tudo.

Para se tentar o tratamento do doente mental, utilizam-se medicamentos para mantê-lo calmo e passivo. Porém, os medicamentos utilizados muitas vezes não são os que possuem um melhor resultado. Às vezes, um único medicamento é usado em quase todos os internados, com síndromes diferentes, trazendo efeitos colaterais mais enérgicos. Isso ocorre pela carência de verbas em muitos hospitais psiquiátricos e manicômios, por se tratarem de instituições públicas, e, principalmente, devido à estrutura de formação dessas instituições: foram criadas para abrigar os exilados da sociedade, os ineptos a ela, os indivíduos que devem ser esquecidos por todos. Assim, essa sociedade que os elimina pouco se importa em investir nos doentes mentais, em trazer melhoras para sua condição; prefere gastar recursos com o que está mais próximo dela, como construções civis, investimentos no mercado etc. 
Dessa forma, todos esses problemas citados ajudam a consolidar o preconceito social, reafirmando para a sociedade e para o próprio doente mental que ele é um ser inútil, que deve ser mantido longe do centro social. Cada vez mais, os manicômios tornam-se instituições que se desviam do suposto fim: a cura, ou pelo menos a busca de um meio para readaptar o doente na sociedade, transformandose em depósitos humanos.

\section{O FRACASSO NA INTERNAÇÃO DO LOUCO CRIMINOSO}

Depois de comprovada a periculosidade do doente mental, este será encaminhado para os hospitais psiquiátricos, os manicômios judiciários, para que não cause males à sociedade e consiga, mediante um tratamento, se tornar inofensivo, obter sua cura.

A cura seria a ressocialização do indivíduo. O tratamento seria dar condições para que o indivíduo, após um trabalho com todo o seu psíquico, adquira consciência das normas sociais, respeitando-as.

Mas o que se percebe é uma utopia a essas idéias, pois se divergem dos resultados obtidos da prática. Os manicômios judiciários cada vez mais possuem pacientes que se eternizam no local. Muitas vezes não por serem indivíduos "altamente perigosos", capazes das piores atrocidades, mas por serem esquecidos pela sociedade. Os manicômios judiciários tornaram-se verdadeiros depósitos humanos. A sociedade não tem outro local disponível para "alojar" os doentes mentais, sendo que o principal problema, que era separar os anormais dos normais, ela já solucionou, por meio dos manicômios, não havendo nenhuma preocupação posterior a esse fato.

Ademais, as famílias de muitos internados não têm condições físicas e sociais para cuidar de um doente mental. Grande parte dos internados em manicômios judiciários públicos são membros de família com renda inferior a três salários mínimos. Assim, a situação do doente mental se agrava, pois, além da discriminação pelos distúrbios psíquicos, sofre também a exclusão social que todo membro de uma camada pobre recebe. As famílias, então, preferem deixá-los eternamente nos manicômios. 
Outro ponto é o almejo da cura. Primeiramente, os manicômios judiciários recebem poucos recursos do governo, ficando o tratamento ambulatorial prejudicado, seja pela carência de remédios, pelas precárias instalações, pela inexistência de terapias ocupacionais, seja pela falta de preparo da equipe dirigente, que não recebe instruções adequadas para lidar com o doente mental.

Outras instituições sociais que poderiam dar apoio, como escolas de medicina, que poderiam oferecer assistência material, médica e humana, ignoram o problema. Tal fato foi aludido no livro Trem de Doido, de Virgílio de Mattos (1999), em entrevista ao Dr. Leonardo José Tollendal, perito-psiquiatra do Manicômio Judiciário de Barbacena, sobre os estudantes da Faculdade de Medicina próxima ao internato: "O Dr. Tollendal ainda se queixou da pouca vocação dos estudantes de medicina, no que tange ao trabalho no manicômio (...) ". (MATTOS, 1999, p.22).

Mas a grande questão se concentra na incapacidade de muitos internados de conseguirem a cura. Para muitos doentes mentais a cura esperada pela sociedade nunca se realizará, pois o organismo do indivíduo não permite. Não há como modificar o psíquico do ser, implantando noções de consciência moral e social.

Com isso, por essa maneira de ser diferente dos outros, tais indivíduos recebem uma pena, por serem assim, sendo "castigados" com um internamento eterno, até a morte do indivíduo. A medida de segurança acaba por se tornar bastante similar à pena:

A medida de segurança, por seu turno, não se distingue da pena: ela também representa perda de bens jurídicos e pode ser, inclusive, mais aflitiva do que a pena, por ser imposta por tempo indeterminado. Toda medida coercitiva imposta pelo Estado, em função do delito e em nome do sistema de controle social, é pena, seja qual for o nome ou a etiqueta com que se apresenta. (PIEDADE JÚNIOR, 1982, p.217).

Dever-se-ia ter um limite para a internação do doente mental. Se um imputável que tem consciência do ato ilícito que lesa um bem jurídico, tendo culpa ou dolo, acaba por ter sua pena fixada em um limite, o inimputável, que nem consciência do mal causado tem, não pode ser punido eternamente. Quando não se determina que a medida de segurança só cessará quando terminar a periculosidade do agente, efetiva-se o poder de punir do Estado de uma maneira abusiva, infinita.

Uma das soluções encontradas seria a dada por Zaffaroni (1997). Para este doutrinador, a duração da medida de segurança deveria ser fixada até o tempo 
correspondente à pena máxima do crime cometido pelo louco criminoso. Não haveria pena perpétua, e o indivíduo, se representasse ainda perigo para a sociedade, passaria a ser controlado por medicamentos.

Assim, para a sociedade alcançar seus objetivos, mantém os indivíduos que não são úteis a ela exilados, enclausurados, com a justificativa de representarem perigo à ordem social. E por essa justificativa, permite-se violar preceitos constitucionais, como a dignidade humana, a proibição de prisões perpétuas, a liberdade de ir e vir.

\section{CONCLUSÃO}

A inclusão do doente mental em hospitais psiquiátricos, em manicômios judiciários, não só é autorizada por toda sociedade, como também defendida fervorosamente. Tal fato decorre da campanha feita em relação ao perigo que o louco traz a todos.

Mas, primeiramente, o que se percebe é uma sociedade preconceituosa que tende a excluir o diferente. $O$ doente mental é um indivíduo que tende a não seguir os padrões normais que todos normalmente seguem, causando uma repulsa nos indivíduos "normais".

Além disso, analisando no âmbito socioeconômico, o doente mental não tem o espírito capitalista do trabalho exacerbado com intuito de lucro e consumismo. Assim, ele se torna uma peça desencaixada no sistema, não sendo útil, só representando gastos.

Com isso, o louco como elemento inválido e "anormal" acaba por ser eliminado do convívio social. A justificação é a periculosidade, que se transformou em um rótulo predeterminado a todos os doentes mentais. Contudo, o que se percebe é que nem todos os doentes mentais são loucos homicidas, perversos, capazes das piores atrocidades.

A maioria dos loucos que estão presentes em Manicômios Judiciários são inofensivos, necessitando apenas de um tratamento, seja medicinal, seja humano, como carinho e atenção. Grande parte dos internados vem de camadas pobres da sociedade, o que só evidencia a exclusão social pelo louco, o pobre, pelo diferente.

Dentro de muitas instituições o doente mental acaba por perder por completo seu papel social. É tratado como ser inválido ou objeto incapaz de aprender ou receber qualquer atenção. A equipe dirigente não age imparcialmente, avaliando o internado como ser ainda perigoso. 
Parte desse conceito de perigo vem de uma doutrina de Direito Penal de Defesa Social, que não se preocupa em proteger o indivíduo, mas defender os interesses sociais, que se revelam em interesses de uma classe dominante. O Direito Penal age como controlador social, instrumento de efetivação do poder.

O Direito Penal deveria defender as garantias conquistadas pelo homem ao longo dos tempos, como a liberdade de ir e vir, de ser diferente, a dignidade humana, contra uma possível opressão a esses direitos. Porém, o que ocorre é o inverso, sendo o louco exemplo de tal fato, excluído, esquecido, recebendo muitas vezes um tratamento que se torna eterno, já que acaba por ficar internado até a sua morte, pois a denominada periculosidade não cessara nunca em determinados casos.

O Direito Penal acaba não por punir um ato que lesa um bem jurídico, mas pelo que o indivíduo é ou representa. Assim, o Direito Penal deveria se limitar à culpabilidade, não enclausurando o indivíduo só pelo que ele é eternamente. Assim, este trabalho propõe a extinção da medida de segurança, por sua inviabilidade, por ser apenas um meio de exclusão do louco.

Se um preso, que tem consciência do crime que cometeu, sabe da duração de sua pena e é posto em liberdade, não deveria o louco, um inimputável, que não tem consciência do que faz, receber um tratamento eterno.

Um preso é colocado em liberdade e tem chances de cometer um novo crime, o louco também. Porém, a medicina já dispõe de medicamentos que controlam possíveis distúrbios - por exemplo medicamentos que deixam o louco dopado, incapaz de qualquer ato contra outro ser.

Proponho que o louco é apto para se manter no convívio social, sendo que, necessitando de tratamento, o tenha em liberdade. O louco não pode ser punido pelo que é, pois é um ser humano e merece dignidade como qualquer um.

\section{REFERÊNCIAS}

BARATTA, Alessandro. Criminologia crítica e crítica do direito penal. Introdução à sociologia do direito penal. Tradução: Juarez Cirino dos Santos, Rio de Janeiro: Revan,1997.

FERRARI, Eduardo Reale. As Medidas de Segurança Criminais e sua Progressão Executória: desinternação progressiva. Boletim Ibccrim, [S.I.], v.8, n.99, p.9-11, fev. 2001. 
FERRARI, Eduardo Reale. Medidas de Segurança e Direito Penal no Estado Democrático de Direito. São Paulo: Revista dos Tribunais, 2001. 229p.

FOUCAULT, Michel. Vigiar e punir. A história da violência nas prisões. 3. ed. Petrópolis, RJ: Vozes, 1984.

GOFFMAN, Erving. Manicômios, Prisões e Conventos. São Paulo: Perspectiva, 2001, 312p.

HUNGRIA, Nelson. Pena e medida de segurança. Revista Forense, [S.I.], v. 100, n. 496/498, p. 419427, out./dez. 1944.

MATTOS, Virgílio. Trem de doido. Belo Horizonte: Uma Editora, 1999. 180p.

PAIM, Isaias. A crueldade da Medida de segurança: idéias, debates e ensaios. Jornal Brasileiro de Psiquiatria, Rio de Janeiro, v. 46, n.10, p.515-521 out. 1997.

PIEDADE JÚNIOR, Heitor. Personalidade psicopática, semi-imputabilidade e medida de segurança. Rio de Janeiro: Forense, 1982. 253p.

PRADO, Luís Regis. Curso de Direito Penal Brasileiro - parte geral. 2. ed. [S.I.]:ver., atual. e ampl.. São Paulo: Ed. Revista dos Tribunais, 2001.

ROMANI, Dagoberto. Semi-imputabilidade aplicação apenas da medida de segurança; desnecessidade de aplicação da pena privativa de liberdade e subsequente substituição pela medida de segurança. Revista dos Tribunais, São Paulo, v.75, n.605, p.437-439, mar. 1986.

SILVA, Alberto José Tavares Vieira da. Extinção das medidas de segurança para os imputáveis. In: ANAIS DO 1. CONGRESSO BRASILEIRO DE POLÍTICA CRIMINAL E PENITENCIÁRIA, Brasília : Ministério da Justiça, Conselho Nacional de Política Penitenciária, 1982. v. 1, p. 273-280.

TRISTÃO, Adalto Dias. Sentença Criminal: prática de aplicação de pena e medida de segurança. 5. ed. rev., atual. e ampl. Belo Horizonte : Del Rey, 2001. 548p.

ZAFFARONI, Eugênio Raúl. Parte Geral.[et.] PIERANGELI, José Henrique. Curso de Direito Penal Brasileiro. São Paulo: Ed. Revista dos tribunais, 1997. 